\title{
CONSUlTA INDÍGENA Y PROCEDIMIENTO DE EVALUACIÓN DE IMPACTO AMBIENTAL. ANÁLISIS DE UNA RELACIÓN NORMATIVA
}

[Consultation to Indigenous Communities and Environmental Impact Assessment Procedure. Analysis of a Regulatory Relationship]

\author{
Juan Pablo Leppe Guzmán* \\ Universidad Católica de Temuco, Chile
}

\begin{abstract}
RESUMEN
El artículo analiza el régimen jurídico dado a la consulta indígena en el marco del Sistema de Evaluación de Impacto Ambiental e intenta una aproximación práctica a las correspondientes fuentes. Se revisa la conformación de tal régimen, sus características, la técnica normativa de que da cuenta y la coherencia interna que exhibe.
\end{abstract}

Palabras clave

Palabras clave: Consulta indígena evaluación de impacto ambiental.

\section{ABSTRACT}

The article analyses the judicial regime given to the consultation to indigenous communities within the context of the Environmental Impact Assessment System and attempts a practical approach to the respective sources. This work reviews the constitution of said regime, its characteristics, regulatory technique and internal consistency.

\section{KeYWORDS}

Consultation to Indigenous Communities- Environmental Impact Assessment.

RECIBIDO el 25 de enero y ACEPTADO el 25 de mayo de 2015

* Licenciado en ciencias jurídicas por la Universidad Diego Portales; diplomado en proceso penal por la Universidad Alberto Hurtado y en derecho ambiental por la Pontificia Universidad Católica de Valparaíso; máster avanzado en ciencias jurídicas por la Universidad Pompeu Fabra, España. Profesor de derecho público en la Universidad Católica de Temuco; Dirección postal: Avenida Patricio Lynch № 930, Valdivia, Los Ríos, Chile. Correo electrónico: jpleppe@yahoo.com 


\section{INTRODUCCIÓN}

En el sistema jurídico chileno, desde el año 1997 en adelante, los proyectos y actividades listados en el artículo 10 de la Ley $\mathrm{N}^{\circ} 19.300$ sobre Bases generales del medio ambiente, deben ser sometidos por sus titulares al Sistema de Evaluación de Impacto Ambiental en forma previa a su ejecución o modificación, por la vía de una declaración de impacto ambiental o de un estudio de impacto ambiental.

Las tipologías de proyectos y los efectos que ameritarán la presentación de un estudio de impacto ambiental en lugar de una declaración de impacto ambiental se encuentran desarrollados en el Reglamento del sistema de evaluación de impacto ambiental. El que además comprende, entre otras materias, la regulación de los distintos procedimientos de evaluación de impacto ambiental ${ }^{1}$.

De otro lado, al suscribir el Convenio $\mathrm{N}^{\circ} 169$ sobre Pueblos indígenas $y$ tribales en países independientes, emanado por la Organización Internacional del Trabajo, el Estado de Chile ha adquirido el deber de llevar a cabo procesos de consulta indígena cada vez que se prevea la emisión de medidas legislativas o administrativas susceptibles de afectar en forma directa a uno o más pueblos indígenas ${ }^{2}$.

Así las cosas, y considerando que los llamados mega proyectos productivos o extractivos con impacto ambiental se localizan en áreas del territorio determinadas, escogidas por ser propicias para la ejecución de los mismos; se tiene que un número importante de proyectos de inversión afecta, o puede terminar afectando, a pueblos indígenas vistos como colectividad o a sus miembros considerados en forma individual.

Esta relación/tensión ha sido abordada por la Presidencia de la República mediante normas de rango reglamentario, con el presumible propósito de acotarla y dotarla de certeza jurídica. Nos referimos aquí al nuevo Reglamento para el sistema de evaluación de impacto ambientaß, aprobado con el Decreto supremo $N^{\circ}$ 40/2012, del Ministerio del Medio

\footnotetext{
${ }^{1}$ En el presente artículo se trabajará con las normas y reglas del procedimiento ordinario de evaluación.

${ }^{2}$ El Convenio $\mathrm{N}^{\circ} 169$ fue promulgado por medio del Decreto supremo $\mathrm{N}^{\circ}$ 236/2008, del Ministerio de Relaciones Exteriores, y se encuentra vigente en Chile desde septiembre de 2009.

${ }^{3}$ Para una aproximación crítica desde la perspectiva de los derechos humanos, véase la minuta del Instituto Nacional de Derechos Humanos, aprobada por su Consejo en mayo de 2013, titulada El Deber de consulta previa en la propuesta de reglamento del sistema de evaluación ambiental [visible en internet: http://www.politicaspublicas.net/panel/docs/indh-informe-consulta-y-reglamento-seia.pdf]
} 
Ambiente ${ }^{4}$ al Reglamento especifico de la consulta, aprobado en el artículo 1 del Decreto Supremo No 66/2013, del Ministerio de Desarrollo Social 5 .

Es en ese contexto que se ha querido llevar a cabo el presente de trabajo, con el cual se busca analizar el diálogo entre ambos cuerpos normativos, dando cuenta de los problemas y debilidades que pueden evidenciar su interpretación y aplicación práctica.

\section{Procedencia de LA CONSULta}

Sobre este punto, el inciso $1^{\circ}$ del artículo 8 del "Reglamento de la consulta" contiene una remisión a la normativa ambiental contenida en la ley $\mathrm{N}^{\circ} 19.300$ y "su reglamento" " "La resolución de calificación ambiental de los proyectos o actividades que ingresan al Sistema de Evaluación de Impacto Ambiental, de conformidad a lo establecido en el artículo 10 de la ley $N^{\circ}$ 19.300, y que requieran un proceso de consulta indígena según lo dispuesto en dicha normativa y su reglamento, se consultarán de acuerdo a la normativa del Sistema de Evaluación de Impacto Ambiental [...]".

En el artículo 85 Regl. Seia, a su turno, se establece que: "Sin perjuicio de lo establecido en el artículo 83 de este Reglamento, en el caso que el proyecto o actividad genere o presente alguno de los efectos, características o circunstancias indicados en los artículos 7, 8 y 10 de este Reglamento, en la medida que se afecte directamente a uno o más grupos humanos pertenecientes a pueblos indigenas el Servicio deberá, de conformidad al inciso segundo del artículo 4 de la Ley, diseñar y desarrollar un proceso de consulta de buena fe, que contemple mecanismos apropiados según las características socioculturales propias de cada pueblo y a través de sus instituciones representativas, de modo que puedan participar de manera informada y tengan la posibilidad de influir durante el proceso de evaluación ambiental. De igual manera, el Servicio establecerá los mecanismos para que estos grupos participen durante el proceso de evaluación

${ }^{4} \mathrm{~A}$ su respecto véase el recurso de protección rol No 19.995 - 2012, deducido por personas naturales indígenas ante la Corte de Apelaciones de Santiago, impugnando el Reglamento para el sistema de evaluación de impacto ambiental durante su proceso de elaboración. Asimismo véase el requerimiento de Diputados de la República ante el Tribunal Constitucional, rol $\mathrm{N}^{\circ} 2523$ - 13, solicitando al Tribunal ejerciera su competencia señalada en el art. $93 \mathrm{~N}^{\circ} 16$ C.Pol. en relación con el mismo cuerpo de normas.

${ }^{5}$ Para una aproximación crítica a su proceso de formación, véase el Informe intermedio de observación a la Mesa de Consenso Indígena del Instituto Nacional de Derechos Humanos [visible en internet: http://www.politicaspublicas.net/panel/ docs/INDH-Informe-intermedio-mesa-de-consenso-17-04-2013.pdf]

${ }^{6}$ No obstante la precitada ley tiene aparejada más de un reglamento, se trataría del Reglamento para el sistema de evaluación de impacto ambiental en este caso. 
de las aclaraciones, rectificaciones y/o ampliaciones de que pudiese ser objeto el Estudio de Impacto Ambiental'.

De esta manera, si nos atenemos a las normas antes transcritas, los proyectos con impacto ambiental que darán origen a un proceso de consulta solo serán aquellos sometidos a evaluación vía estudio de impacto ambiental; en la medida que generan o presentan efectos, características o circunstancias previstos en los literales c) $\left.{ }^{7}, \mathrm{~d}\right)^{8}$ y f) ${ }^{9}$ del artículo 11 de la ley $\mathrm{N}^{\circ} 19.300^{10}$; y que se espere motiven la adopción de una medida administrativa que revista la forma y el contenido de una resolución de calificación ambiental, causante de la afectación directa de uno o más pueblos indígenas o grupos humanos pertenecientes a estos.

Ahora bien, qué debe entenderse por afectación directa? A este respecto el artículo 7 del Reglamento de consulta aporta dos criterios: uno formal, y otro material.

Conforme con el primero, las medidas administrativas susceptibles de afectar en forma directa a los pueblos indígenas serían los actos administrativos terminales de naturaleza discrecional. Actos que en el marco del procedimiento de evaluación de impacto ambiental de proyectos serán las respectivas resolución de calificación ambiental favorables asociadas a ellos ${ }^{11}$, como se verá con mayor detenimiento en el acápite siguiente.

El criterio material, por su parte, dice relación con aquellos actos que encuadrándose en las descripciones dadas más arriba; el punto está tratado en el artículo 7 , inciso $3^{\circ}$, última parte: "[...] sean causa directa de un impacto significativo y específico sobre los pueblos indígenas en su calidad de

${ }^{7}$ Reasentamiento de comunidades humanas, o alteración significativa de los sistemas de vida y costumbres de grupos humanos.

${ }^{8}$ Localización en o próxima a poblaciones, recursos y áreas protegidas, sitios prioritarios para la conservación, humedales protegidos y glaciares, susceptibles de ser afectados, así como el valor ambiental del territorio en que se pretende emplazar.

${ }^{9}$ Alteración de monumentos, sitios con valor antropológico, arqueológico, histórico y, en general, los pertenecientes al patrimonio cultural.

${ }^{10}$ Desarrollados en los artículos 7, 8 y 10 Regl. Seia. En este punto véanse los artículos 5, 6 y 9 Regl. Seia. y las remisiones que ellos contienen a su vez, a los artículos 7 y 8 del mismo cuerpo de normas.

${ }^{11}$ La naturaleza jurídica específica del acto administrativo denominado "resolución de calificación ambiental" no es un punto pacífico en la doctrina. Al respecto véanse las posiciones de los autores nacionales Bermúdez, Jorge, Fundamentos de derecho ambiental (Valparaíso, Ediciones Universitarias de Valparaíso, 2007; hay una edición posterior), pp. 207 ss.; Astorga, Eduardo, Derecho ambiental chileno. Parte general (Santiago, LexisNexis, 2006, hay una edición posterior), pp. 220 ss.; y GuZMÁn, Rodrigo, Derecho ambiental chileno. Principios, Instituciones, Instrumentos de gestión (Santiago, Editorial Planeta Sostenible, 2012), pp. 159 ss. 
tales, afectando el ejercicio de sus tradiciones y costumbres ancestrales, prácticas religiosas, culturales o espirituales, o la relación con sus tierras indigenas" ${ }^{\prime 2}$.

En relación con el último criterio, cabe acotar que la enumeración que sigue a la descripción misma de la afectación tendría un carácter orientativo y a título ejemplar, toda vez que el mecanismo de la consulta procedería ante afectaciones genéricas que se prevea puedan experimentar los pueblos originarios o sus miembros como efecto de medidas administrativas o legislativas. Especialmente, frente a afectaciones que se visualice puedan experimentar sus intereses y el ejercicio de los derechos que expresa y desarrolla el Convenio $\mathrm{N}^{\circ} 169$ (quedando comprendidos en éste, por ejemplo, aquellos que se desprenden de los artículos 14, 15 y 16 del tratado ${ }^{13}$ ), como efecto de medidas estatales que se vayan a adoptar en forma prospectiva.

\section{OBJETO DE LA CONSULTA}

El objeto o materia de los procesos de consulta serán las resolución de calificación ambiental que se espera se dicten declarando ambientalmente favorables proyectos o actividades sometidos a evaluación vía estudio de impacto ambiental, que ameriten la realización de uno de tales procesos a la luz de la normativa ambiental concordada con la propia del mecanismo consultivo.

En este punto, el "Reglamento de la consulta" no deja lugar a dudas en el inciso $1^{\circ}$ de su artículo 8: "Medidas que califican proyectos o actividades que ingresan al Sistema de Evaluación de Impacto Ambiental"14, pese a contener un error de redacción. Dice: "La resolución de calificación ambiental de los proyectos o actividades que ingresen al Sistema de Evaluación

${ }^{12}$ Para conocer interpretaciones que han hecho tribunales superiores de justicia de la denominada "susceptibilidad de afectación directa", pueden verse, entre otras, las sentencias recaídas en las Acciones de Protección Rol Nº 436 - 2013 (Corte de Apelaciones de Copiapó), y 179 - 2014 (Corte de Apelaciones de Puerto Montt).

${ }^{13}$ Sobre la materia véase Arístegui, Juan Pablo - Del Fierro, Francisca - Guiloff, Matías, Convenio 169 de la OIT sobre Pueblos Indígenas y Tribales en Países Independientes. Cuestiones generales e implicancias en relación con la gestión de los recursos naturales; en Hervé, Dominique - PÉrez, Raimundo (coordinadores), Cuaderno de Análisis Jurídico sobre Derecho Ambiental y Políticas Públicas (Santiago, Universidad Diego Portales, Colección de Derecho Ambiental, 2011), I, pp. 407 ss.

${ }^{14}$ Sin perjuicio que se ubica en el contexto de un razonamiento judicial extenso, contenido en una sentencia definitiva, parece discutible la afirmación de la Corte de Antofagasta en el sentido que la resolución de calificación ambiental de una actividad "no constituye una medida legislativa o administrativa" (Considerando $9^{\circ}$ de sentencia recaída en el recurso rol N ${ }^{\circ} 1637$ - 2013, confirmada por la Corte Suprema en febrero de 2014). 
de Impacto Ambiental, de conformidad a lo establecido en el artículo 10 de la ley $N^{\circ} 19.300$, y que requieran un proceso de consulta indigena según lo dispuesto en dicha normativa y su reglamento, se consultarán de acuerdo a la normativa del Sistema de Evaluación de Impacto Ambiental [...]".

Lo anterior se aviene con el criterio formal de carácter general contenido en el inciso $3^{\circ}$ del artículo 7 Regl. Consul., conforme con el cual, las medidas administrativas susceptibles de afectar en forma directa a los pueblos indígenas son "aquellos actos formales dictados por los órganos que formen parte de la Administración del Estado y que contienen una declaración de voluntad, cuya propia naturaleza no reglada permita a dichos órganos el ejercicio de un margen de discrecionalidad que los habilite para llegar a acuerdos u obtener el consentimiento de los pueblos indígenas en su adopción [...]".

En este punto se aclara que el objeto de la consulta no serán resolución de calificación ambiental ya dictadas, previamente, por el director ejecutivo del Servicio de Evaluación Ambiental o por una Comisión Regional de Evaluación Ambiental, según el caso; sino más bien, los estudio de impacto ambiental de proyectos que desencadenan procesos administrativos encaminados a la dictación de una resolución de calificación ambiental ${ }^{15}$.

De hecho, dando aplicación al criterio general del artículo 7 debe entenderse que "los actos de mero trámite y las medidas de ejecución material o jurídica se entenderán comprendidas en la consulta del acto terminal o decisorio al que han servido de fundamento o que deban aplicar".

\section{IMPULSO DE PROCESOS Y DECISIÓN DE LLEVARLOS A CABO}

Según lo prescrito en el artículo 13 Regl. Consul., esta última podrá ser decretada de oficio por el "órgano responsable", o a solicitud fundada de cualquier persona interesada o institución representativa, sin perjuicio que la Corporación Nacional de Desarrollo Indígena pueda solicitar se evalúe la procedencia de iniciar un proceso.

Con todo, se prevé la posibilidad que el órgano concernido solicite un informe de procedencia a la Subsecretaría de Servicios Sociales del Ministerio de Desarrollo Social, organismo que contará con un plazo máximo de 10 días hábiles para cumplir evacuando el documento.

En este punto, y sin perjuicio de la amplitud con que se permite solicitar la realización de una consulta, cabe agregar que el Convenio $\mathrm{N}^{\circ} 169$ OIT. delimita su ámbito de aplicación en su artículo 1, especificándose en

${ }^{15}$ Ello es consistente con uno de los principios de la consulta recogido en forma expresa en el Reglamento, cual es el de su carácter previo (artículo 11). 
él qué se entiende por pueblos tribales y por pueblos indígenas en países independientes ${ }^{16}$.

Luego, el Reglamento para el sistema de evaluación de impacto ambiental comprende una definición para los efectos del mismo Reglamento, con arreglo a la cual: "se consideran pueblos indígenas, aquellos que define el artículo $N^{\circ} 1$, literal b) del Convenio 169 de la OIT, reconocidos en el artículo primero inciso segundo de la ley $19.253^{17}$. Se entenderá que un individuo tiene la calidad de indígena cuando cumpla con lo establecido en el artículo $2^{\circ}$ de la ley $N^{\circ} 19.253^{18}$. A su vez, se considerará que los individuos señalados en el inciso anterior podrán constituir grupos humanos en los términos del artículo $7^{\circ}$ del presente reglamento, independientemente de su forma de constitución u organización"19 20 .

${ }^{16} \mathrm{El}$ artículo $1 \mathrm{~N}^{\circ} 1$, reza: "El presente Convenio se aplica:/ a) a los pueblos tribales en países independientes, cuyas condiciones sociales, culturales y económicas les distingan de otros sectores de la colectividad nacional, y que estén regidos total o parcialmente por sus propias costumbres o tradiciones o por una legislación especial./ b) a los pueblos en paises independientes, considerados indigenas por el hecho de descender de poblaciones que habitaban en el país o en una región geográfica a la que pertenece el país en la época de la conquista o la colonización o del establecimiento de las actuales fronteras estatales y que, cualquiera sea su situación juridica, conserven todas sus propias instituciones sociales, económicas, culturales y políticas, o parte de ellas".

17 "El Estado reconoce como principales etnias indígenas de Chile a la mapuche, aimara, rapa nui o pascuenses, la de las comunidades atacameñas, quechuas, collas y diaguita del norte del país, las comunidades kawashkar o alacalufe y yámana o yagán de los canales australes".

18 "Se considerarán indígenas para los efectos de esta ley, las personas de nacionalidad chilena que se encuentren en los siguientes casos: a) Los que sean hijos de padre o madre indígena, cualquiera sea la naturaleza de su filiación, inclusive la adoptiva./ Se entenderá por hijos de padre o madre indígena a quienes desciendan de habitantes originarios de las tierras identificadas en el artículo 12, números 1 y $2 . /$ b) Los descendientes de las etnias indigenas que habitan el territorio nacional, siempre que posean a los menos un apellido indígena.I Un apellido no indígena será considerado indígena, para los efectos de esta ley, si se acredita su procedencia indígena por tres generaciones, y/ c) Los que mantengan rasgos culturales de alguna etnia indigena, entendiéndose por tales la práctica de formas de vida, costumbres o religión de estas etnias de un modo habitual o cuyo cónyuge sea indigena. En estos casos, será necesario, además, que se autoidentifiquen como indígenas".

${ }^{19}$ Artículo $\mathrm{N}^{\circ} 2$ letra h).

${ }^{20}$ En el inciso final del artículo 85 Regl. Seia., por su parte, se establece que: “En caso que no exista constancia que un individuo tenga la calidad de indigena conforme a la ley $N^{\circ} 19.253$, deberá acreditar dicha calidad según lo dispuesto en la normativa vigente". 


\section{DiReCCión de los PROCESOS DE CONSUlta}

En primer lugar, cabría tener aquí presente el encabezado mismo del artículo 6 del Convenio $\mathrm{N}^{\circ} 169$, conforme con el cual el deber de consultar recae sobre los gobiernos, de modo que la dirección y el desarrollo de los procesos de consulta enmarcados en procesos de evaluación de impacto ambiental no serán de cargo de los titulares de los proyectos o actividades sometidos al Sistema de Evaluación de Impacto Ambiental, sino del órgano de la Administración del Estado que intervenga en aquél.

En el Reglamento que se regula el procedimiento de consulta, ahora, se enumera a los órganos a los cuales se aplica, quedando comprendidos "los ministerios, las intendencias, los gobiernos regionales, las gobernaciones y los servicios públicos creados para el cumplimiento de la función administrativa" ${ }^{21}$.

Luego, y más específicamente en relación con las hipótesis de hecho atingentes al presente trabajo, debe atenderse al tenor literal del artículo 85 Regl. Seia. y al artículo 8 Regl. Consult.

En el primero se establece que "el Servicio deberá, de conformidad al inciso segundo del artículo 4 de la Ley, diseñar y desarrollar un proceso de consulta de buena fe"22.

En el segundo, a su turno, se discurre sobre la base de un supuesto: "para la realización de los procesos de consulta que se realicen en el marco del Sistema de Evaluación de Impacto Ambiental, la autoridad ambiental podrá solicitar la asistencia técnica de la Corporación Nacional de Desarrollo Indigena, en los términos señalados en el artículo 14 de este reglamento".

Por lo tanto, tenemos que durante el desarrollo de procesos de evaluación de impacto ambiental de proyectos que impliquen la dictación de medidas administrativas que afecten o puedan afectar a pueblos indígenas o a sus miembros, el órgano a cargo de impulsar y dirigir los procesos de consulta indígena será "la autoridad ambiental (con la eventual asistencia de la Corporación Nacional de Desarrollo Indígena)", que no sería otra en estos casos que el Servicio de Evaluación Ambiental. Organismo llamado por el legislador a administrar el instrumento de gestión ambiental Sistema de Evaluación de Impacto Ambiental ${ }^{23} 24$.

${ }^{21}$ Artículo 4 inciso $1^{\circ}$.

${ }^{22}$ Lo cual debe ser concordado con el artículo 2, letra i), del mismo Reglamento para el sistema de evaluación de impacto ambiental.

${ }^{23}$ Artículo 81 letra a) de la Ley $\mathrm{N}^{\circ} 19.300$, sobre Bases generales del medio ambiente.

${ }^{24}$ En la práctica, el Servicio de Evaluación Ambiental se ha apoyado también en otros órganos públicos, como son las Municipalidades. Lo cual contaría con fundamento normativo en virtud de lo dispuesto en el artículo 83 , inciso $2^{\circ}$ Regl. Seia. 


\section{EL PROCEDIMIENTO Y SUS REGLAS}

En el artículo 8 inciso $1^{\circ}$ Regl. Consul., se lee que las resoluciones de calificación ambiental correspondientes "[...] se consultarán de acuerdo a la normativa del Sistema de Evaluación de Impacto Ambiental, dentro de los plazos que tal normativa establece, pero respetando el artículo 16 del presente instrumento en lo que se refiere a las etapas de dicha consulta" 25.

El Reglamento para el sistema de evaluación de impacto ambiental, por su parte, establece que si el proyecto o actividad lo ameritan, el Servicio de Evaluación Ambiental "[...] deberá, de conformidad al inciso segundo del artículo 4 de la Ley ${ }^{26}$, diseñar y desarrollar un proceso de consulta de buena fe, que contemple mecanismos apropiados según las caracteristicas socioculturales propias de cada pueblo y a través de sus instituciones representativas, de modo que puedan participar de manera informada y tengan la posibilidad de influir durante el proceso de evaluación ambiental. De igual manera, el Servicio establecerá los mecanismos para que estos grupos participen durante el proceso de evaluación de las aclaraciones, rectificaciones y/o ampliaciones de que pudiese ser objeto el Estudio de Impacto Ambiental./ En el proceso de consulta a que se refiere el inciso anterior, participarán los pueblos indigenas afectados de manera exclusiva y deberá efectuarse con la finalidad de llegar a un acuerdo o lograr el consentimiento. No obstante, el no alcanzar dicha finalidad no implica la afectación del derecho a la consulta" 27.

Así constatamos que el Servicio de Evaluación Ambiental se encuentra habilitado normativamente para diseñar procedimientos particulares, caso a caso. Sin perjuicio de lo cual, no podría omitir las etapas que establece el "Reglamento de la consulta" (planificación del proceso de consulta; entrega de información y difusión del proceso de consulta; deliberación interna de los pueblos indígenas; diálogo y, sistematización, comunicación de resultados y término del Proceso ${ }^{28}$ ), como tampoco podría prescindir de los principios recogidos en forma expresa para efectos de informar los

${ }^{25}$ Cuales son: planificación del proceso de consulta; entrega de información y difusión del Proceso de consulta; deliberación interna de los pueblos indígenas; diálogo y, sistematización, comunicación de resultados y término del Proceso de consulta.

${ }^{26}$ En el cual se prescribe: "Los órganos del Estado, en el ejercicio de sus competencias ambientales y en la aplicación de los instrumentos de gestión ambiental, deberán propender por la adecuada conservación, desarrollo y fortalecimiento de la identidad, idiomas, instituciones y tradiciones sociales y culturales de los pueblos, comunidades y personas indígenas, de conformidad a lo señalado en la ley y en los convenios internacionales ratificados por Chile y que se encuentren vigentes".

${ }^{27}$ Incisos $1^{\circ}$ y $2^{\circ}$.

${ }^{28}$ Enumeradas y desarrolladas en el artículo 16. 
procedimientos (buena fe, procedimiento apropiado y carácter previo de la consulta ${ }^{29}$.

Por último, al no observarse en las normas transcritas un marco temporal que delimite la extensión de los procesos, habría que recurrir a las normas generales para contar con uno, encontrándose respecto de las medidas administrativas en el "Reglamento de la consulta", que "cada una de las etapas [del proceso de consulta] deberá ser ejecutada en un plazo no superior a 20 dias hábiles./ Sin perjuicio de lo anterior, el órgano responsable de la medida, previo diálogo con las instituciones representativas de los pueblos indigenas susceptibles de ser afectados directamente, podrá, en la etapa de planificación, modificar los plazos señalados por motivos justificados, considerando la necesidad de establecer procedimientos flexibles que se adecuen a las circunstancias propias de cada consulta en particular"30.

\section{COMPARACIÓN ENTRE LA PARTICIPACIÓN CIUDADANA Y LA CONSULTA INDÍGENA ${ }^{31}$}

Uno de los deberes que le impuso el legislador ambiental al Estado considerado en su conjunto, es facilitar la participación ciudadana ${ }^{32}$, e inserta en el marco del procedimiento de evaluación de impacto ambiental, la participación de la comunidad recibe el trato normativo de instrumento de gestión ambiental ${ }^{33}$.

${ }^{29}$ Desarrollados en los artículos 9,10 y 11 , respectivamente.

${ }^{30}$ Artículo 17 inciso $1^{\circ}$ letra b), e inciso $2^{\circ}$.

${ }^{31}$ Comparación sobre la base de la regulación vigente para cada una.

${ }^{32} \mathrm{El}$ artículo 4 inciso $1^{\circ}$ de la Ley $\mathrm{N}^{\circ} 19.300$, prescribe: "Es deber del Estado facilitar la participación ciudadana, permitir el acceso a la información ambiental y promover campañas educativas destinadas a la protección del medio ambiente". Según AsEnjo, Rafael, Consideraciones sobre participación ciudadana, en AsTORGA, Eduardo - Cubillos, Gonzalo (editores), Aspectos jurídicos de la gestión ambientalmente adecuada de residuos (Santiago, Memorias del Seminario Nacional de Derecho Ambiental, Fundación Friedrich Ebert/CEPAL, 1993) p. 133: "La participación ciudadana es, además, un proceso en que no se está ante una realidad de blanco o negro, todo o la nada. Es un proceso en el que hay grados, que, evidentemente, va desde el autoritarismo centralizador absoluto, donde todas las decisiones las toma un caballero o una señora, hasta el extremo que algunos han llamado democratitis, o para hacerlo referente al término que estamos discutiendo, podríamos llamar participacionitis, la cual es paralizante, claramente manipuladora, además de ineficientes e ineficaz [...]".

${ }^{33}$ Dentro del título $2^{\circ}$ de la ley $\mathrm{N}^{\circ} 19.300$, "De los instrumentos de gestión ambiental", encontramos su párrafo $3^{\circ}$, que lleva por epígrafe: "De la participación de la comunidad en el procedimiento de evaluación de impacto ambiental". Para una definición del concepto instrumento de gestión ambiental, véase el libro citado de Bermúdez (n. 11), p. 140; y para una definición de gestión ambiental, véase FER- 
En cuanto a la consulta, ahora, se estima que ella sería una expresión especialísima de la participación de la comunidad durante el procedimiento ordinario de evaluación, que en atención de su objeto, principios, procedimiento y sujetos debía contar con un mecanismo y un régimen jurídico distintos de la participación ciudadana, considerada en esta materia la regla general (al ser concebida para la generalidad de los casos y sin consideración de pueblos o grupos humanos determinados) $)^{34}$.

Si se atiende a la regulación de una y otra, se observa que la participación ciudadana comprende una serie de derechos, tales como el de acceder y conocer el expediente físico o electrónico de la evaluación, el derecho a formular observaciones y el derecho a obtener respuesta fundada de las mismas. Una consulta, por su parte, debe dar aplicación a los principios que la rigen y facilitar la participación informada de los grupos humanos específicos afectados, permitiéndoles influir en forma efectiva durante el proceso de evaluación ambiental.

En cuanto al tiempo de duración, y tomando como punto de partida la regulación de los estudios de impacto ambiental, se tiene que los procesos de participación ciudadana aparejados a ellos comprenden el derecho de formular observaciones al documento por un plazo de 60 días, contado desde la publicación del respectivo extracto ${ }^{35}$. Los procesos de consulta, por su parte (y como se viera más arriba), constan de 5 etapas, las que podrían llegar a extenderse, en principio, hasta por un total de 100 días hábiles $^{36}$.

En cuanto a la etapa en que tienen lugar, la participación ciudadana relativa a un estudio de impacto ambiental se dará en una etapa inicial de

NÁNDEZ, Pedro, Manual de derecho ambiental chileno (Santiago, Editorial Jurídica de Chile, 2004), pp. 153 ss.

${ }^{34}$ Sin perjuicio de lo cual, se entiende que tanto la PAC como la consulta englobarían casi los mismos derechos constitucionales, debiendo añadirse a la consulta -si el supuesto de hecho específico lo amerita-, el derecho a la igualdad ante la ley. En este punto Fernández cuenta: la libertad de opinión, el derecho a reunión, el derecho de petición, el derecho de asociación y el derecho a vivir en un medio ambiente libre de contaminación. FernándeZ, P., cit. (n. 33), p. 168.

${ }^{35}$ El artículo 29 de la ley $\mathrm{N}^{\circ} 19.300$ también prevé la posibilidad que como consecuencia de ICASARAS y ADENDAS, se termine afectando en forma sustantiva los proyectos, y en razón de ello se deba abrir una segunda etapa de participación ciudadana por un plazo de 30 días.

${ }^{36}$ De acuerdo con estudio elaborado (para la Organización Internacional del Trabajo) por Abogabir, Matías, Estudio de Caso Chile, Convenio $N^{\circ} 169$ de la OIT y la consulta a los pueblos indígenas en proyectos de inversión, p. 54, un universo de 16 procesos arrojaba a septiembre de 2014 una duración promedio de 280 días [visible en internet: http://www.cpc.cl/wp-content/uploads/2014/10/141016EstudioCa soChileOITCapitulosI-II-III-IV.pdf] 
la evaluación ambiental y la consulta debiera hacer lo propio, abarcando eso sí un espacio de tiempo mayor. Ahora bien, se prevé la necesidad de establecer mecanismos adicionales para que los grupos humanos pertenecientes a pueblos indígenas afectados puedan participar durante el proceso de evaluación de las aclaraciones, rectificaciones o ampliaciones de que pueda ser objeto un estudio de impacto ambiental, aunque estas no impliquen una modificación sustantiva del proyecto o actividad, o de los impactos ambientales que ellos generan o presentan ${ }^{37} 38$.

Desde el punto de vista subjetivo, en una etapa de participación ciudadana puede intervenir cualquier persona natural o jurídica. Lo que equivale a decir instituciones, colectividades y personas individualmente consideradas. En un proceso de consulta, en cambio, solo podrán tomar parte grupos humanos que reúnan las características y presenten las condiciones desarrolladas en forma previa, pero no en forma directa, sino a través de sus instituciones representativas.

Desde el punto de vista de los efectos que producen una y otra, la participación ciudadana faculta a quienes formulan observaciones para exigir que estas sean evaluadas y consideradas en el informe consolidado de evaluación, quedando habilitados para reclamar ante el Comité de Ministros si sus observaciones no fueran debidamente consideradas (lo que permitirá después dar por agotada la vía administrativa y ocurrir ante el Tribunal Ambiental competente, con arreglo al artículo 20 inciso $4^{\circ}$ de la ley $\mathrm{N}^{\circ} 19.300$ ).

El desarrollo de una consulta, por su lado, debe quedar plasmado en un expediente, cuyo informe final, a lo menos, debiera ser tenido en cuenta y ponderado en la calificación misma del estudio de impacto ambiental respectivo.

Por último, y atendido el tenor literal del artículo 85 Regl. SEIA (que trata sobre la consulta a pueblos indígenas), nada obstaría a que un mismo estudio de impacto ambiental diera origen tanto a una etapa de participación ciudadana como a un proceso de consulta indígena, en forma paralela. Lo cual encontraría justificación en el hecho que los participantes de uno y otro difieren de un modo tal, que la diferencia permite establecer una relación género - especie entre los mecanismos.

${ }^{37}$ Artículo 85 Regl. Seia. inciso $1^{\circ}$, última parte.

${ }^{38}$ Frente a modificaciones sustantivas que experimente el estudio de impacto ambiental, se prevé la apertura de una segunda etapa de la consulta ciudadana y de una segunda consulta acotada, en el artículo 92 Regl. Seia. 


\section{COMENTARIOS FINALES}

Parece indiscutible que la tarea que asume un Estado al hacerse parte de un tratado como el Convenio $\mathrm{N}^{\circ} 169$ es una de grandes proporciones, y desde el año 2009 en adelante el Estado de Chile ha venido haciendo esfuerzos con miras a cumplir con la obligación asumida ante la comunidad internacional y los pueblos originarios.

Específicamente en lo que dice relación con la implementación de la consulta indígena en el marco de la evaluación de proyectos con impacto ambiental, puede recordarse que se modificó primero el artículo 4 de la ley $\mathrm{N}^{\circ} 19.300$ en 2010 señalándosele un deber a los órganos estatales, y más recientemente, se dictó el nuevo Reglamento del sistema de evaluación de impacto ambiental y luego uno con que se regula el procedimiento de la consulta Indígena.

De esta manera, se cuenta con un régimen jurídico configurado por etapas sucesivas, con distintas fuentes normativas, y que ha quedado constituido, predominantemente, por normas de rango reglamentario, lo que por cierto obedece a una decisión de política pública.

A mayor abundamiento, la regulación vigente del procedimiento de consulta no incorpora las normas del artículo 34 de la llamada "Ley Indígena" $\left(\mathrm{N}^{\circ} 19.253^{39}\right)$, a diferencia de su antecedente más directo, el Decreto supremo $N^{\circ} 124 / 2009$ del entonces Ministerio de Planificación, que llevaba por título: "Reglamenta el artículo 34 de la ley $\mathrm{N}^{\circ} 19.253$, a fin de regular la consulta y la participación de los pueblos indígenas" ${ }^{\text {" }}$.

Desde un punto de vista material, se observa que solo se ha pretendido regular el mecanismo contenido en el Convenio $\mathrm{N}^{\circ} 169$ OIT., y más específicamente, se ha pretendido implementar en el orden interno el mecanismo que contempla el instrumento en su artículo $6 \mathrm{~N}^{\circ} 1$, letra a) y $\mathrm{N}^{\circ} 2^{41}$. Conformándose un sistema de normas que no se agota en los

${ }^{39}$ Establece normas sobre protección, fomento y desarrollo de los indígenas y crea la Corporación Nacional de Desarrollo Indígena. El artículo 34 de la ley se inserta en su párrafo $1^{\circ}$, que lleva por epígrafe "De la participación indígena", el cual a su vez, forma parte del título $5^{\circ}$ de aquella, "Sobre la participación", y dispone: "Los servicios de la administración del Estado y las organizaciones de carácter territorial, cuando traten materias que tengan injerencia o relación con cuestiones indigenas, deberán escuchar y considerar la opinión de las organizaciones indígenas que reconoce esta ley".

${ }^{40}$ Reglamento derogado en forma expresa en el artículo segundo del Reglamento en vigor.

${ }^{41}$ Sobre este punto, véase: ANAYA, James, Acápite 1 de sección B, de “Comentarios del relator especial sobre los derechos de los pueblos indígenas en relación con el documento titulado: "Propuesta de gobierno para nueva normativa de consulta y participación indígena de conformidad a los artículos $6^{\circ}$ y $7^{\circ}$ del Convenio $N^{\circ} 169$ de la Organización 
artículos 85 Regl. Seia, y $8^{\circ}$ del Decreto Supremo Nº 66/2013, concordados con el artículo 4 de la ley $\mathrm{N}^{\circ} 19.300$, el articulado del Convenio $\mathrm{N}^{\circ} 169$ y, eventualmente, el de la Ley $\mathrm{N}^{\circ} 19.253$.

De hecho, el desarrollo que se hace en el mismo Reglamento para el sistema de evaluación de impacto ambiental de los efectos, características y circunstancias del artículo 11 de la Ley sobre bases generales del medio ambiente, intercala reglas especiales aplicables en relación con "grupos humanos pertenecientes a pueblos indígenas", y además de ello, reconduce a artículos próximos ${ }^{42}$, todo lo cual termina dificultando la aprehensión que pueden hacer los titulares de su derecho a procesos consultivos, y en segundo término, dificulta el manejo y aplicación de las normas por parte de operadores e intérpretes.

Lo anterior reviste importancia si reparamos en el hecho que el Reglamento para el sistema de evaluación de impacto ambiental acota la procedencia de procesos de consulta solo a ciertos proyectos sometidos a evaluación vía estudio de impacto ambiental ${ }^{43}$, lo que debiera obedecer también a una razón de política pública si se considera que la gran mayoría de proyectos sometidos al Sistema de Evaluación de Impacto Ambiental ingresa vía declaración de impacto ambiental. Con todo, la realidad podría demostrar que proyectos que no generan los efectos del artículo 11 de la ley $\mathrm{N}^{\circ} 19.300$, sí motivan la dictación de una resolución de calificación ambiental capaz de afectar, en un caso concreto y en forma directa, a pueblos indígenas ${ }^{44}$.

En lo tocante a las situaciones de hecho que las normas comentadas regulan, podría haberse previsto con mayor profundidad la situación de los grupos humanos que deciden retirarse de un proceso iniciado, regulándose

Internacional del Trabajo", Chile" (2012) [visible en internet: http://unsr.jamesanaya.org/special-reports/comentarios-a-la-propuesta-del-normativa-de-consulta-chile]

${ }^{42} \mathrm{El}$ artículo 5 reconduce al 8 y los artículos 6 y 8 reconducen, por su parte, a los artículos 7 y 8.

${ }^{43} \mathrm{El}$ artículo $86 \mathrm{Regl}$. Seia, establece sí la obligación para las autoridades del Servicio de Evaluación Ambiental, de celebrar reuniones con los grupos humanos pertenecientes a pueblos indígenas localizados en el área en que se desarrollarán proyectos o actividades, en la medida que estos últimos ingresen a evaluación (vía estudio de impacto ambiental), no den origen a un proceso consultivo, y se emplacen en tierras indígenas, áreas de desarrollo indígena, o en las cercanías de los grupos humanos precitados. Ello con la finalidad de recoger opiniones, analizarlas y, eventualmente, ponerle término anticipado al correspondiente proceso de evaluación, pudiendo motivarse una de estas decisiones e incluso la resolución de calificación ambiental que se dicte en las actas de las reuniones.

${ }^{44}$ Más aún si se tiene presente que a partir de 2010 se reconoce legalmente la posibilidad de abrir etapas de participación ciudadana en relación con proyectos y actividades sometidos a evaluación vía declaración de impacto ambiental. 
los pasos a seguir por el órgano responsable del desarrollo de la consulta y las consecuencias derivadas. Si bien las normas aparejadas al principio de la buena fe (artículo 9) y al expediente (artículo 19) se aproximan a dicha hipótesis fáctica, no establecen consecuencias frente al retiro de un proceso por parte de un grupo, lo que puede propiciar la judicialización ${ }^{45}$.

En cuanto a la regulación de los procesos concluidos, se estima que a futuro podría establecerse un control jurisdiccional tanto del debido desarrollo de ellos como del cumplimiento de los acuerdos alcanzados.

De esa manera podría velarse por la realización de procesos ajustados a principios y reglas predeterminados; evitarse procesos testimoniales que carezcan de una incidencia real, y entregarse el conocimiento de las controversias que surjan a órganos especializados como son los Tribunales Ambientales ${ }^{46}$. Con esto último se lograría una equiparación de los estándares propios de la consulta indígena con los de la participación ciudadana (lo que parece condición de posibilidad para aplicar aquí en forma adecuada el principio de isonomía), junto con lo cual podría evitarse que por la vía de la acción constitucional de protección se dilate inútilmente la autorización definitiva de proyectos, mientras conoce y resuelve la justicia ordinaria en una potencial doble instancia.

\section{BiBLIOGRAFÍA}

Abogabir, Matías. 2014. Estudio de Caso Chile, Convenio $N^{\circ} 169$ de la OIT y la consulta a los pueblos indigenas en proyectos de inversión [visible en internet: http:// www.cpc.cl/wp-content/uploads/2014/10/141016EstudioCasoChileOITCapit ulosI-II-III-IV.pdf]

AnAya, James. 2012. "Comentarios del Relator Especial (James Anaya) sobre los derechos de los pueblos indígenas en relación con el documento titulado: 'Propuesta de gobierno para nueva normativa de consulta y participación indigena de conformidad a los artículos $6^{\circ}$ y $7^{\circ}$ del Convenio $N^{\circ} 169$ de la Organización Internacional del Trabajo', Chile" [visible en internet: http://unsr.jamesanaya.org/special-reports/ comentarios-a-la-propuesta-del-normativa-de-consulta-chile]

Arístegui, Juan Pablo - Del Fierro, Francisca - Guiloff, Matías, Convenio 169 de la OIT sobre Pueblos Indígenas y Tribales en Paises Independientes. Cuestiones generales e implicancias en relación con la gestión de los recursos naturales; en Hervé, Dominique - Pérez, Raimundo (coordinadores), Cuaderno de Análisis Jurídico sobre derecho ambiental y politicas públicas (Santiago, Universidad Diego Portales, Colección de Derecho Ambiental, 2011).

${ }^{45}$ Véase al respecto el supuesto de hecho que motivó la presentación ante de la Corte de Apelaciones de Santiago del recurso de protección rol $N^{\circ} 19.839$ - 2014, y la sentencia recaída en él.

${ }^{46}$ En relación con este punto véase la sentencia de la Corte de Apelaciones de Arica en el recurso rol No $215-2014$. 
AsEnjo, Rafael, Consideraciones sobre participación ciudadana, en Astorga, Eduardo y Cubillos, Gonzalo (editores), Aspectos jurídicos de la gestión ambientalmente adecuada de residuos (Santiago, Memorias del Seminario Nacional de Derecho Ambiental, Fundación Friedrich Ebert/CEPAL, 1993).

Astorga, Eduardo, Derecho ambiental chileno. Parte general (Santiago, LexisNexis, 2006).

Bermúdez, Jorge, Fundamentos de derecho ambiental (Valparaíso, Ediciones Universitarias de Valparaíso, 2007).

FernándeZ, Pedro, Manual de derecho ambiental chileno (Santiago, Editorial Jurídica de Chile, 2004).

GuZmán, Rodrigo, Derecho ambiental chileno. Principios, instituciones, instrumentos de gestión (Santiago, Editorial Planeta Sostenible, 2012). 